\title{
A review of the TOPHAT (Turned-down Onto Pericapsular-tissue Hemisectioned Amputated Toe) filleted toe flap technique for wound coverage during ray amputations
}

\author{
Nadia Sim \\ Singapore General Hospital \\ Shaun Lee \\ Singapore General Hospital \\ Hao Yun Yap \\ Singapore General Hospital \\ Qian Ying Tan \\ Singapore General Hospital \\ Jerilyn Tan \\ Singapore General Hospital \\ Daniel Wong
}

Singapore General Hospital

Amanda Chau

Singapore General Hospital

Manfred Mak

Singapore General Hospital

Tze Tec Chong

Singapore General Hospital

Hsien Ts'ung Tay ( $\nabla$ tay.hsien.tsung@singhealth.com.sg )

Singapore General Hospital

\section{Research}

Keywords: fillet flap, desiccation, toe-salvage, vacuum assisted closure, topical negative pressure wound therapy, wound

Posted Date: October 2nd, 2020

DOI: https://doi.org/10.21203/rs.3.rs-84107/v1 
License: (c) (i) This work is licensed under a Creative Commons Attribution 4.0 International License. Read Full License 


\section{Abstract}

Background: Wound healing post ray amputation for toe gangrene is commonly complicated by adjacent digital loss after applying Topical Negative Pressure Wound Therapy (TNPWT). This is either due to mechanical soft tissue erosion or trauma to the adjacent digital artery from direct pressure effect. This ultimately results in exposure of the adjacent Metatarsal-Phalangeal Joint (MTPJ) with eventual gangrene and a larger wound bed, thus mandating further ray amputation and subsequently enlarge the wound bed. We describe the use of the TOPHAT filleted toe flap technique - a combination of a filleted toe flap to protect the adjacent MTPJ capsule and a novel Negative Pressure Wound Therapy with instillation and dwell-time (NPWTi-d) dressing technique. The fillet flap protects the adjacent joint capsule and reduce the wound burden whilst allowing the wound to benefit from TNPWT, thereby accelerating wound healing.

Methods: We conducted a prospective review of patients with toe gangrene requiring ray amputations who underwent the TOPHAT filleted toe flap technique in our institution from 2019 and 2020. Complications such as wound dehiscence, hematoma, flap necrosis and secondary infection were recorded. Other outcomes recorded were time taken to final skin grafting and time taken for complete wound epithelialisation.

Results: 9 patients underwent treatment with the TOPHAT filleted toe flap technique between 2019 and 2020. 2 patients had minimal tip necrosis of the flap which required minor debridement. All except 2 patients whom declined further treatment, progressed to definitive skin coverage with skin grafting. One patient had progressive arterial disease despite successful skin grafting and required above knee amputation. The mean time to final skin grafting was 49.5 days post-operatively and the mean time to final wound epithelialisation was 107.5 days post-operatively. Patients were all satisfied with the outcomes and were able to return to pre-morbid function.

Conclusions: The TOPHAT filleted toe flap technique has a consistent vascular supply that provides durable soft tissue coverage. It is a robust and easily reproducible technique to accelerate wound healing after ray amputations even in patients with peripheral vascular disease.

\section{Background}

The diabetic foot often coexists with peripheral vascular disease and results in osteomyelitis or digital gangrene necessitating single or multiple ray amputations. Topical Negative Pressure Wound Therapy (TNPWT) is commonly employed to accelerate healing of the resultant wound cavities. However, this often results in erosion of soft tissue or trauma to the adjacent digital arteries, causing the adjacent Metatarsal-Phalangeal Joint (MTPJ) capsule to be exposed with eventual toe gangrene and a larger wound bed. Some surgeons prefer to allow secondary wound healing in the foot of the vasculopath or diabetic however this can take a long time if the tissue defect is large and runs the risk of re-occlusion of 
revascularized vessels, causing wound deterioration. This inadvertently increases the frequency of dressing changes, cost of wound care ${ }^{1}$ and exposure to late recurrent infections ${ }^{2}$.

To circumvent the effects of the TNPWT on the adjacent joint capsule whilst still allowing it to accelerate wound healing on the wound bed, we employ the concept of Spare-Part surgery ${ }^{3}$ using a toe fillet flap from the adjacent toe. We describe a minor mobilisation of the toe fillet as a turned-down flap to an adjacent bed (TOPHAT - Turned-down Onto Pericapsular-tissue Hemisectioned Amputated Toe). This is used in combination with Negative Pressure Wound Therapy with instillation and dwell-time (NPWTi-d). This fillet flap serves to protect the adjacent joint capsule and reduce the wound burden whilst allowing the wound to benefit from TNPWT, thereby accelerating wound healing.

\section{Methods}

With centralized institutional review board (CIRB) approval, we conducted a prospective review of patients who were treated with the TOPHAT filleted toe flap technique at Singapore General Hospital between 2019 and 2020. Demographic data such as gender, age, race, and co-morbidities were recorded. Complications such as wound dehiscence, hematoma, flap necrosis and secondary infection were recorded.

\section{Patient criteria}

To minimize the risk of flap necrosis and post-procedural infection, we only attempted the TOPHAT filleted toe flap technique when the following criteria were met: (a) ray amputation of the digit was justified because of bone involvement of the metatarsal head or shaft or soft tissue to the metatarsalphalangeal joint, (b) the contralateral half of skin flap was healthy and viable for use as a turn down flap.

\section{TOPHAT (Turned-down Onto Pericapsular-tissue Hemisectioned Amputated Toe) filleted toe flap technique}

A dorsal to ventral incision is made on the adjacent digit to hemisection the toe (Fig. 1). The digital bones and metatarsal head and neck, tendon and joint capsule are filleted out from the skin whilst preserving the neurovascular bundle distal to the wound (Fig. 1).

The skin is turned down and circumferentially approximated to the wound bed and adjacent cut skin edges with non-absorbable sutures over the adjacent joint capsule (Fig. 2).

A NPWTi-d instillation therapy (Acelity ${ }^{\mathrm{TM}}$ V.A.C. VERAFLO CLEANSE $\mathrm{CHOICE}^{\mathrm{TM}}$ ) is then applied over the remaining wound bed with a hydrocolloid paste dressing (Coloplast ${ }^{\mathrm{TM}}$ Brava ${ }^{\circledR}$ Strip Paste) to establish a water-proof seal between the wound and the fillet flap. A bolster dressing made by sandwiching a piece of cut V.A.C foam between 2 pieces of V.A.C drapes is applied over the exposed flap to help it bed the flap down to the wound bed (Fig. 3). 
The choice of instillation fluid is culture dependent ( $0.95 \%$ Normal Saline by default, $0.25 \%$ acetic acid for Pseudomonas Aeruginosa, Mölnlyncke ${ }^{\mathrm{TM}}$ Granuducyn $\rightarrow$ for fungal). The NPWTi-d dressing is applied either at the same time as the flap creation or during the first wound inspection.

Culture directed antibiotic therapy is continued for 1 week or until there are no signs of soft tissue infection. Wound inspection is done on post-operative day 3, 7 and 10 to monitor for wound dehiscence, hematoma, flap necrosis and secondary infection. The patient is kept on a non-weight bearing status for 2 weeks. The NPWTi-d dressing is changed at each wound inspection until the exposed wound bed is deemed to be ready for a final skin coverage with a split skin graft.

6 patients in our series had concomitant lower limb peripheral vascular disease in the ipsilateral limb that required revascularization prior to performing the TOPHAT filleted toe flap technique. They were kept on anti-platelet therapy after revascularization.

\section{Results}

Between 2019 and 2020, 9 patients (7 males and 2 females) were treated with the TOPHAT filleted toe flap technique. The mean age was 58 years ( 41 to 81 years). The clinical demographics of the patients are described in the table below (Table 1). The etiology of the defects was due to sequelae of peripheral vascular disease and/or diabetes mellitus. All our patients had underlying diabetes mellitus. 6 out of 9 patients had peripheral vascular disease of the affected limb that required angioplasty during the same admission.

3 out of 9 of our patients underwent the TOPHAT filleted toe flap technique at the same time as the primary amputation of the affected digits as a portion of the skin on the affected digit remained clinically viable to be used as a turned down fillet flap. The remaining patients underwent NPWTi-d and underwent the TOPHAT filleted toe flap technique subsequently as the capsule of the adjacent metatarsus became gradually desiccated and exposed from the NPWTi-d. In these patients, the fillet flap was obtained from the skin of the digit with the desiccated MTPJ that eventually required amputation.

2 patients developed flap necrosis which required surgical debridement, of which one was extensive and was not salvageable even after debridement due to underlying extensive arterial disease with re-occlusion after angioplasty (Patient 8). One patient decided to terminate treatment due to financial concerns and was lost to follow up (Patient 6). The flap healed completely for the remaining 8 patients with the wound bed ready for final skin graft application. The mean time to final skin coverage from time of TOPHAT was 49.5 days (22 to 95 days).

4 patients underwent split skin grafting (SSG) and 2 underwent Acelity $^{\mathrm{TM}}$ CelluTome $^{\mathrm{TM}}$, one patient declined skin coverage due to financial concerns (Patient 3). 4 out the 6 patients had uneventful wound healing and complete epithelialisation was achieved in a mean duration of 107.5 days (48 to 209 days). One patient developed pressure necrosis over his healed skin graft. One patient (Patient 2) had extensive arterial disease with re-occlusion after angioplasty and subsequently required an above knee amputation. 
Table 1

Demographics and clinical characteristics of patients who underwent TOPHAT Technique

\begin{tabular}{|llllllll|}
\hline $\begin{array}{l}\text { Patient } \\
\text { No. }\end{array}$ & $\begin{array}{l}\text { Age } \\
\text { (years) }\end{array}$ & Gender & $\begin{array}{l}\text { Donor } \\
\text { Toe }\end{array}$ & $\begin{array}{l}\text { Distal } \\
\text { Tip } \\
\text { Necrosis }\end{array}$ & $\begin{array}{l}\text { Skin } \\
\text { Grafting }\end{array}$ & $\begin{array}{l}\text { Time taken to } \\
\text { skin graft* } \\
\text { (days) }\end{array}$ & $\begin{array}{l}\text { Time taken for } \\
\text { wound to } \\
\text { epithelialise* } \\
\text { (days) }\end{array}$ \\
\hline 1 & 61 & F & 2nd & No & Yes & 38 & 64 \\
\hline 2 & 71 & M & 2nd & Yes & Yes & 77 & - \\
\hline 3 & 69 & M & 3rd & No & No & - & 143 \\
\hline 4 & 71 & M & 3rd & No & Yes & 22 & 82 \\
\hline 5 & 48 & M & 3rd & No & Yes & 32 & 99 \\
\hline 6 & 41 & M & 2nd & No & No & - & - \\
\hline 7 & 31 & M & 2nd & No & Yes & 33 & 48 \\
\hline 8 & 48 & M & 5th & Yes & No & - & - \\
\hline 9 & 81 & F & 4th & No & Yes & 95 & 209 \\
\hline Mean & & & & & & \\
\hline *From time of the TOPHAT filleted toe flap technique & & \\
\hline
\end{tabular}

Case Studies

\section{Case study 1, Patient 1}

This is a 61-year-old Malay lady with a history of peripheral vascular disease, type II diabetes mellitus, hypertension, hyperlipidemia and end stage renal failure. She presented with gangrene of the right $3^{\text {rd }}$ to $5^{\text {th }}$ toes (Fig. 4A and Fig. 4B). She had undergone plain old balloon angioplasty (POBA) to her right superficial femoral (SFA), popliteal and posterior tibial (PT) arteries 2 years prior to admission.

She underwent right lower limb angioplasty again with a $2^{\text {nd }}$ to $5^{\text {th }}$ toe ray amputation in the same sitting. The PT was occluded and dorsalis pedis (DP) was severely attenuated with poor outflow to the forefoot. POBA was performed with good flow established to the lateral plantar arch, although distal runoff was still poor. The TOPHAT filleted toe flap technique was performed with fillet flap derived from the medial aspect of the $2^{\text {nd }}$ toe in the same sitting as the skin on the medial aspect of the $2^{\text {nd }}$ toe appeared viable preoperatively.

She underwent SSG on post-operative day 38 (Fig. 5A) with complete wound epithelialisation 64 days from time of TOPHAT (Fig 5B). The big toe remained healthy throughout. 
This is a 69-year-old Malay gentleman with a history of peripheral vascular disease, type II diabetes mellitus, hypertension and hyperlipidemia. He presented with gangrene of his left $1^{\text {st }}$ and $2^{\text {nd }}$ toes. He underwent left lower limb angioplasty with $1^{\text {st }}$ and $2^{\text {nd }}$ ray amputation with good restoration of the plantar arch flow with 2 distal runoffs via the ATA and PTA. NPWTi-d therapy was applied to the wound bed, but the tissue in the region of the $3^{\text {rd }}$ metatarsal head remained unhealthy with eventual desiccation and exposure of the capsule (Fig. 6) which required a $3^{\text {rd }}$ toe ray amputation. He underwent the TOPHAT filleted toe flap technique 2 weeks later with the fillet flap derived from the $3^{\text {rd }}$ toe. The fillet flap healed completed but the patient declined skin grafting due to financial concerns. The wound epithelialized completely 143 days from the time of TOPHAT. The $4^{\text {th }}$ toe remained healthy throughout (Fig. 7).

\section{Discussion}

Fillet flaps are frequently raised as part of the spare part concept ${ }^{4}$ in the reconstruction of weight bearing areas of the foot. It is an axial pattern flap harvested from non-functioning or unsalvageable digits. Described in 1965 by Snyder and Edgerton ${ }^{5}$, filleted islanded neurovascular flaps from the toes and anterior sole were used to resurface neuropathic heel ulcers. Similarly, Kaplan described the use of a filleted big toe flap to cover anterior sole defects in $1969^{6}$.

In a formal ray amputation, the metatarsal head is removed with the digit and the joint capsule of the MTPJ is excised as an exposed capsule impedes granulation of the wound. We apply topical negative pressure wound therapy (TNPWT) to ray amputation wounds to accelerate granulation and healing. However, a substantial proportion of patients have closely-packed metatarsal heads hence the combination of capsule excision with TNPWT on the wound bed results in the gradual exposure of the adjacent joint capsule, with eventual deterioration of the toe necessitating another ray amputation. This can be avoided in the use of the TOPHAT filleted toe flap technique whilst allowing the wound bed to benefit from the granulation promoted by NPWTi-d instillation therapy. We employ the use of a toe fillet flap derived from the non-salvageable sacrificed adjacent toe to protect the same MTPJ. We have shown good results with patients in our series.

The vascular supply of the toe fillet flap has historically been thought to be less reliable compared to that of the finger fillet flap ${ }^{7}$. Coupled with the fears of inadequate perfusion from underlying peripheral vascular disease that most of such patients have, the use of loco-regional flaps in reconstructing post-ray amputation wounds has been largely replaced by TNPWT and eventual skin grafting ${ }^{8}$, or more commonly, leaving the wound to heal by secondary intention. However, secondary wound healing has disadvantages such as a prolonged time of healing in large plantar cavity wounds while continuously exposing the patient to recurrent infection and risks inherent with prolonged off-loading ${ }^{9}$. Frequent dressing changes in this instance also impose high costs and inconvenience to the patient.

The selection criteria for employing fillet toe flaps were developed by Nather and Wong ${ }^{10}$ but are overstringent and exclude patients with significant peripheral arterial disease (one or two palpable pedal 
pulses, ankle brachial index $(A B I) \geq 0.8$ and toe brachial index $\geq 0.7$ ) who form the bulk of these patients. In 2014, Chung et al ${ }^{11}$ presented the use of a toe fillet flap for the coverage of the MTPJ adjacent to the ray amputation wound that had been exposed after the initial debridement. However, their patients were as per Nather and Wong's criteria ${ }^{10}$. In a similar fashion, others such as Aerden et al also selected for patients with no or mild peripheral vascular disease prior to attempting their filleted toe flaps ${ }^{9}$. The majority of patients in our series have severe peripheral vascular disease (critical limb ischemia) and most required endovascular intervention. Yet we were still able to perform the TOPHAT filleted toe flap technique with minimal complications and flap survival rates which we deemed exceptional in this cohort (of vascular surgical patients). The fillet toe flap is a reliable flap for wound coverage despite microangiopathic disease of the plantar digital arteries ${ }^{12}$ and helps decrease the overall wound burden without additional donor site morbidity. We believe that such strict selection criteria are not necessary for selecting for the fillet toe flap because in doing so we will exclude patients who may benefit from it.

With proper wound debridement and subsequent application of NPWTi-d therapy, the wound healing trajectory shifts from delaying wound infection to granulation formation. Even with poorer patient demographics with significant underlying peripheral vascular disease, the mean time to the wound bed being ready for final skin coverage with skin grafting was 49.5 days and the complete wound healing of the entire wound bed in our series was 107.5 days. Other case reports for foot wounds closed entirely with a fillet flap alone reported a healing time of 9-months to 1 year $^{9,11,12}$. Chung et al described a lateral lesser toe fillet flap for the diabetic similar to toe filleting technique with a similar intention to reduce the overall wound burden without the concurrent use of a TNPWT. However, the time taken for complete wound healing in their case report took 6-months ${ }^{11}$. Even with patients with severe arterial disease requiring endovascular intervention, our time to complete wound healing was shorter. We believe that a combination technique using the filleted toe flap and careful "barrier and buttress" NPWTi-d dressing helps accelerate the granulation process and allow for earlier skin grafting and more rapid wound resolution.

The TOPHAT filleted toe flap technique in the management of post ray amputation wounds is a simple and reproducible method that does not require complex microsurgical skills or techniques. The vascular supply is consistent based on the digital arteries of the toes, even in patients with diabetes and peripheral vascular disease ${ }^{13,14}$. Hence it is useful in patients where microsurgery may be difficult and reduces the need for more complex soft tissue reconstructive procedures ${ }^{15,16}$. More studies are warranted to better select patients for the procedure without excluding the cohort of vasculopaths - doppler studies of the digital arteries in the toes designated for amputation may prove useful.

\section{Conclusion}

The TOPHAT filleted toe flap has a consistent vascular supply that provides durable soft tissue coverage. It is a robust and easily reproducible technique to accelerate wound healing after ray amputations in patients with peripheral vascular disease. 


\section{Declarations}

\section{Ethics approval and consent to participate}

This study was approved by the institution's centralized institutional review board (CIRB) approval committee (CIRB 2020/2249)

\section{Consent for publication}

All patients involved in this study consented for their data and images to be used for publication

Availability of data and materials

The datasets generated and/or analyzed during the current study are not publicly available due them containing information that could compromise research participant privacy/consent. But are available from the corresponding author on reasonable request.

\section{Competing Interests}

The authors declare that they have no completing interests

\section{Funding}

The authors declare that there is no funding body involved in the design of the study and collection, analysis and interpretation of data in writing the manuscript

\section{Authors' Contributions}

N Sim and HT Tay were a major contributor in writing the manuscript. All authors read and approved the final manuscript.

\section{Acknowledgements}

Not applicable

Authors' Information

Not applicable

\section{$\underline{\text { Footnotes }}$}

Not applicable

\section{References}


1. Hunt NA, Liu GT, Lavery LA. The economics of limb salvage in diabetes. Plast Reconstr Surg Published online. 2011. doi:10.1097/PRS.0b013e3181fbe2a6.

2. Nehler MR, Whitehill TA, Bowers SP, et al. Intermediate-term outcome of primary digit amputations in patients with diabetes mellitus who have forefoot sepsis requiring hospitalization and presumed adequate circulatory status. J Vasc Surg Published online. 1999. doi:10.1016/S07415214(99)70078-9.

3. Peng YP, Lahiri A. Spare-part surgery. Semin Plast Surg Published online. 2013. doi:10.1055/s-00331360586.

4. Küntscher MV, Erdmann D, Homann HH, Steinau HU, Levin SL, Germann G. The concept of fillet flaps: Classification, indications, and analysis of their clinical value. Plast Reconstr Surg Published online. 2001. doi:10.1097/00006534-200109150-00011.

5. Snyder GB, Edgerton MT. The principle of the island neurovascular flap in the management of ulcerated anesthetic weightbearing areas of the lower extremity. Plast Reconstr Surg Published online. 1965. doi:10.1097/00006534-196511000-00003.

6. Kaplan I. Neurovascular island flap in the treatment of trophic ulceration of the heel. Br J Plast Surg Published online. 1969. doi:10.1016/S0007-1226(69)80055-X.

7. Alpert BS, Buncke HJ. Mutilating multidigital injuries: Use of a free microvascular flap from a nonreplantable part. J Hand Surg Am. Published online 1978. doi:10.1016/S0363-5023(78)80074-4.

8. Noble-Bell G, Forbes A. A systematic review of the effectiveness of negative pressure wound therapy in the management of diabetes foot ulcers. Int Wound J. 2008. doi:10.1111/j.1742481X.2008.00430.x.

9. $10.1177 / 1534734612446640$

Aerden D, Vanmierlo B, Denecker N, Brasseur L, Keymeulen B, Van Den Brande P. Primary closure with a filleted hallux flap after transmetatarsal amputation of the big toe for osteomyelitis in the diabetic foot: A short series of four cases. Int J Low Extrem Wounds. Published online 2012. doi:10.1177/1534734612446640.

10. Nather A, Wong KL. Distal amputations for the diabetic foot. Diabet Foot Ankle Published online. 2013. doi:10.3402/dfa.v4i0.21288.

11. Chung SR, Wong KL, Cheah AEJ. The lateral lesser toe fillet flap for diabetic foot soft tissue closure: Surgical technique and case report. Diabet Foot Ankle Published online. 2014. doi:10.3402/dfa.v5.25732.

12. Morain WD. Island toe flaps in neurotrophic ulcers of the foot and ankle. Ann Plast Surg Published online. 1984. doi:10.1097/00000637-198407000-00001.

13. Lin CH, Wei FC, Chen HC. Filleted toe flap for chronic forefoot ulcer reconstruction. Ann Plast Surg Published online. 2000. doi:10.1097/00000637-200044040-00010.

14. Kalbermatten DF, Kalbermatten NT, Haug M, Schäfer D, Pierer G. Use of a combined pedicled toe fillet flap. Scand J Plast Reconstr Surg Hand Surg. Published online 2004. doi:10.1080/02844310410027211. 
15. $10.1177 / 1938640014560163$

Schade VL. Digital Fillet Flaps: A Systematic Review. Foot Ankle Spec. Published online 2015. doi:10.1177/1938640014560163.

16. Granick MS, Newton ED, Futrell JW, Hurwitz D. The plantar digital web space island flap for reconstruction of the distal sole. Ann Plast Surg Published online. 1987. doi:10.1097/00000637$198707000-00012$.

\section{Figures}

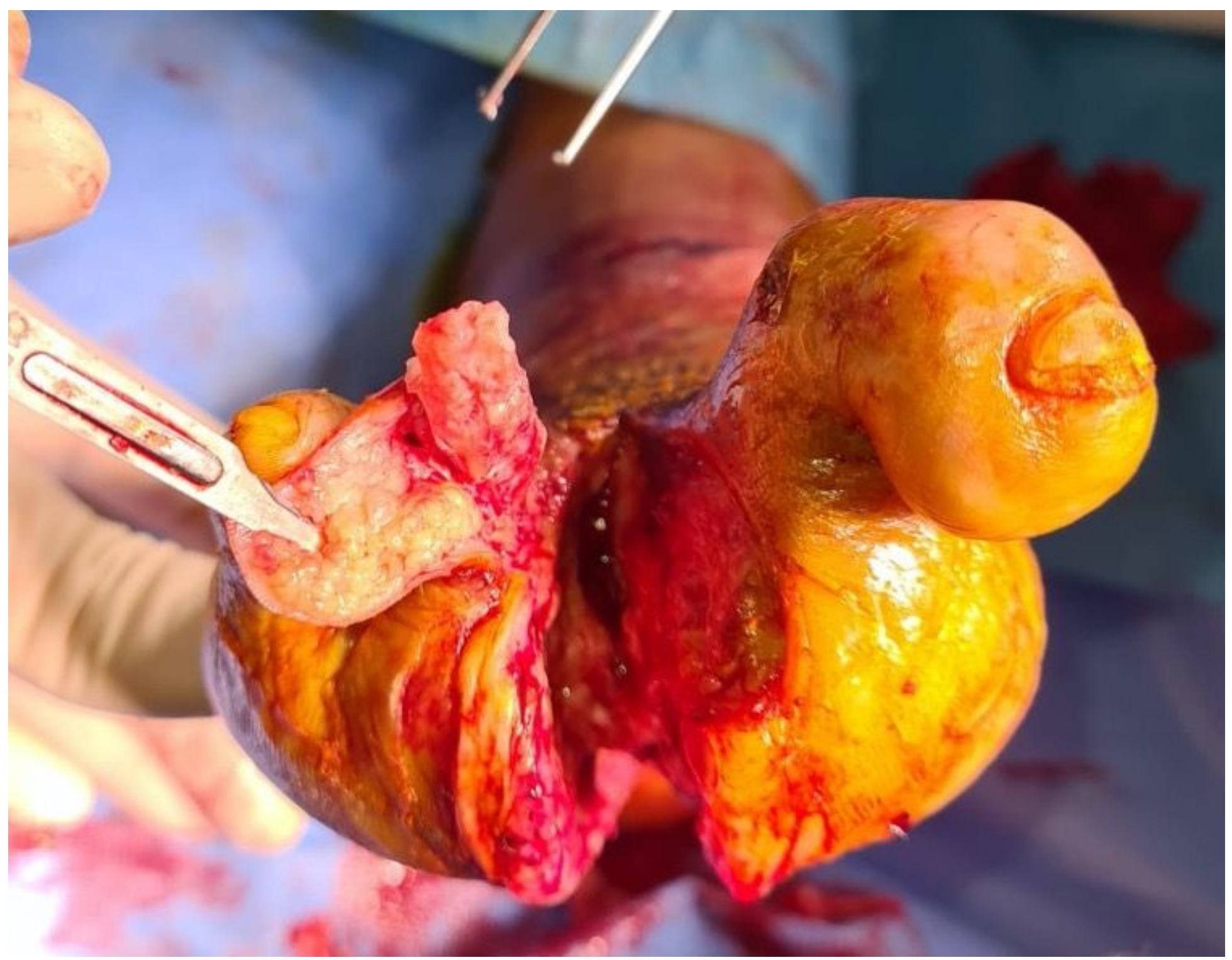

\section{Figure 1}

Bone, tendon and joint capsule filleted out from the skin via a dorsal to ventral incision 


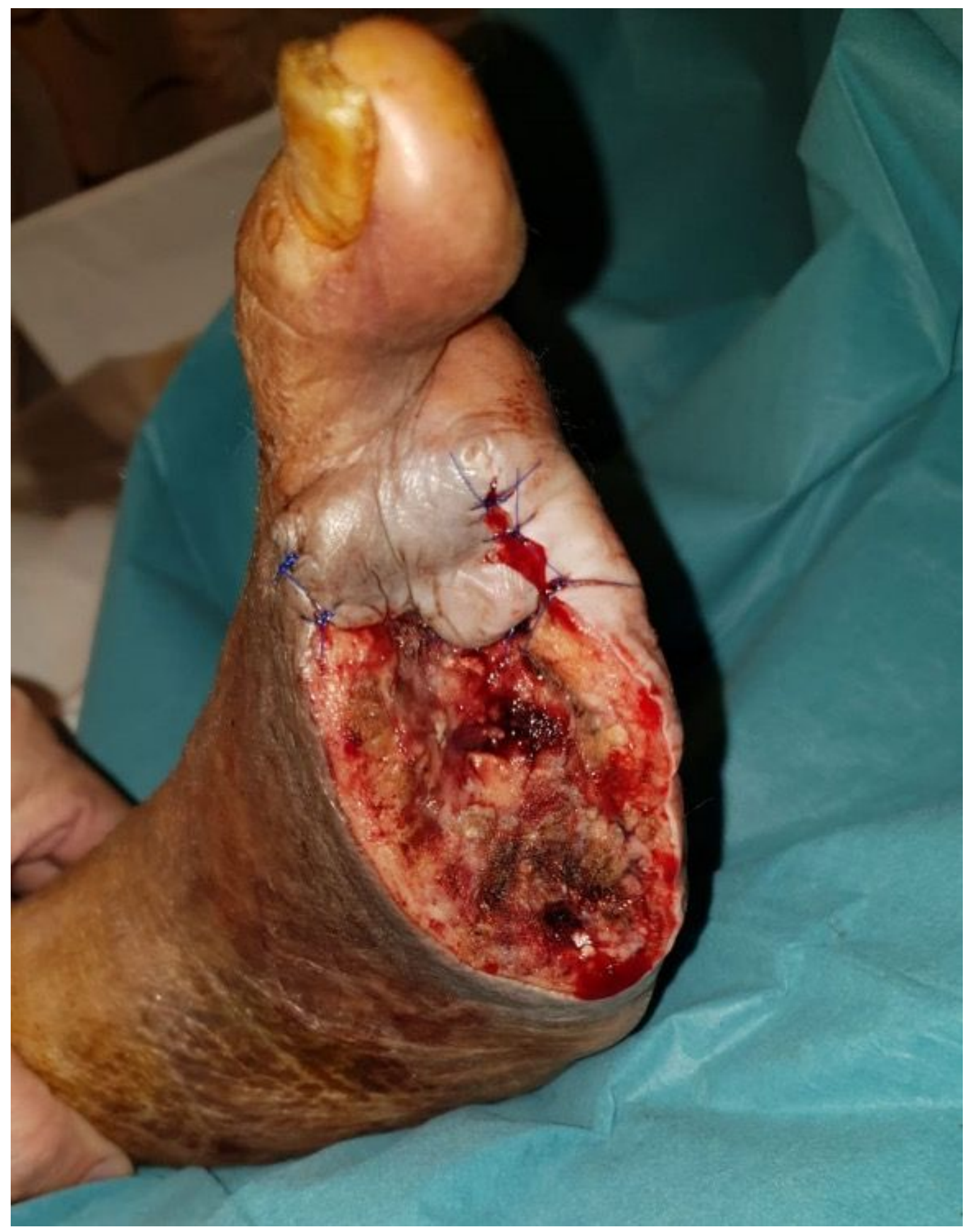

Figure 2

Flap harvested from viable half of amputated toe turned down over the MTPJ 


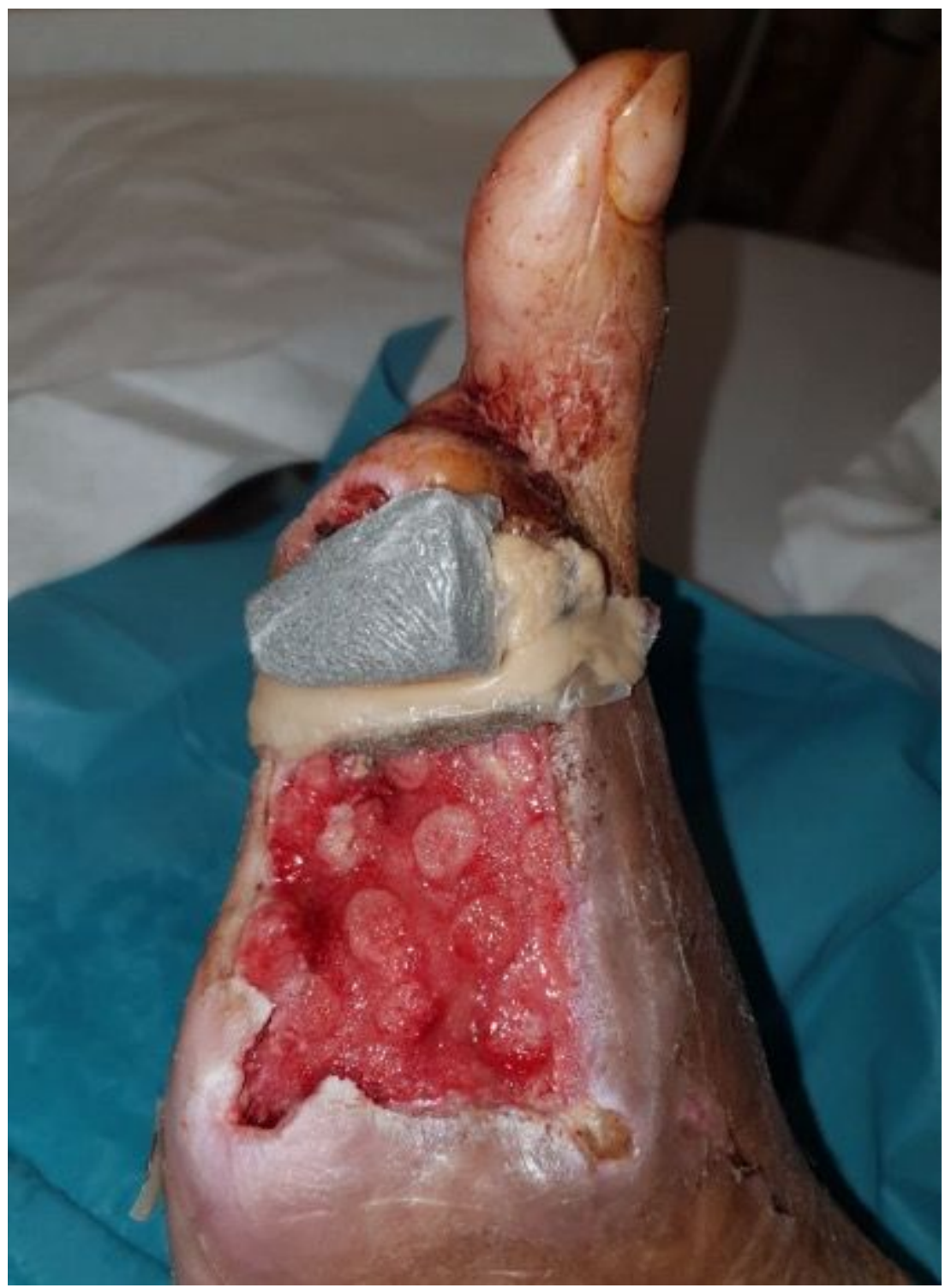

Figure 3

Customized bolster placed onto the flap, with hydrocolloid "dam" dressing 


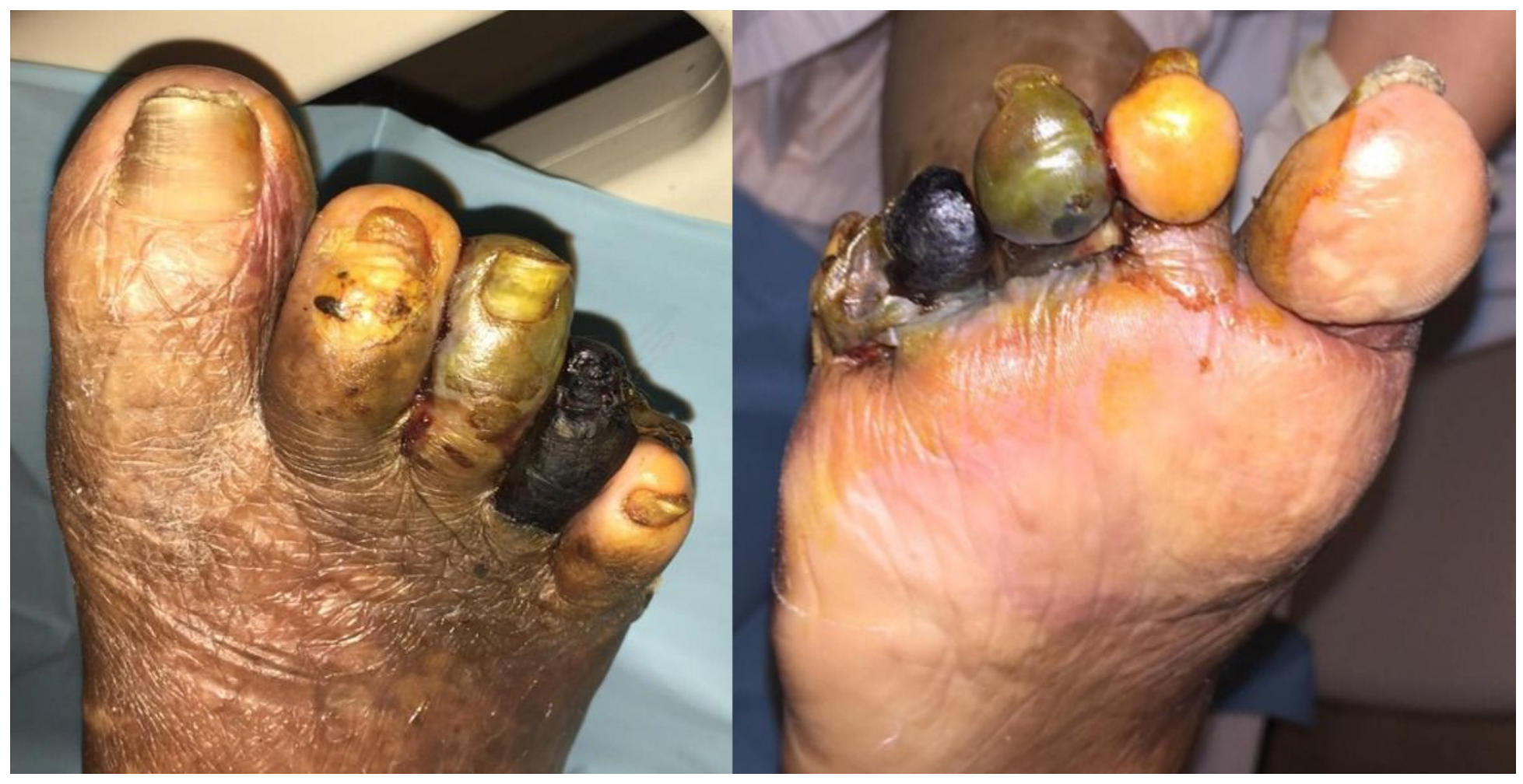

\section{Figure 4}

(Left) A Appearance of the patient's foot at presentation with necrotic 3rd to 5th toes (anterior) (Right) B Appearance of the patient's foot at presentation with necrotic 3rd to 5th toes (posterior) 


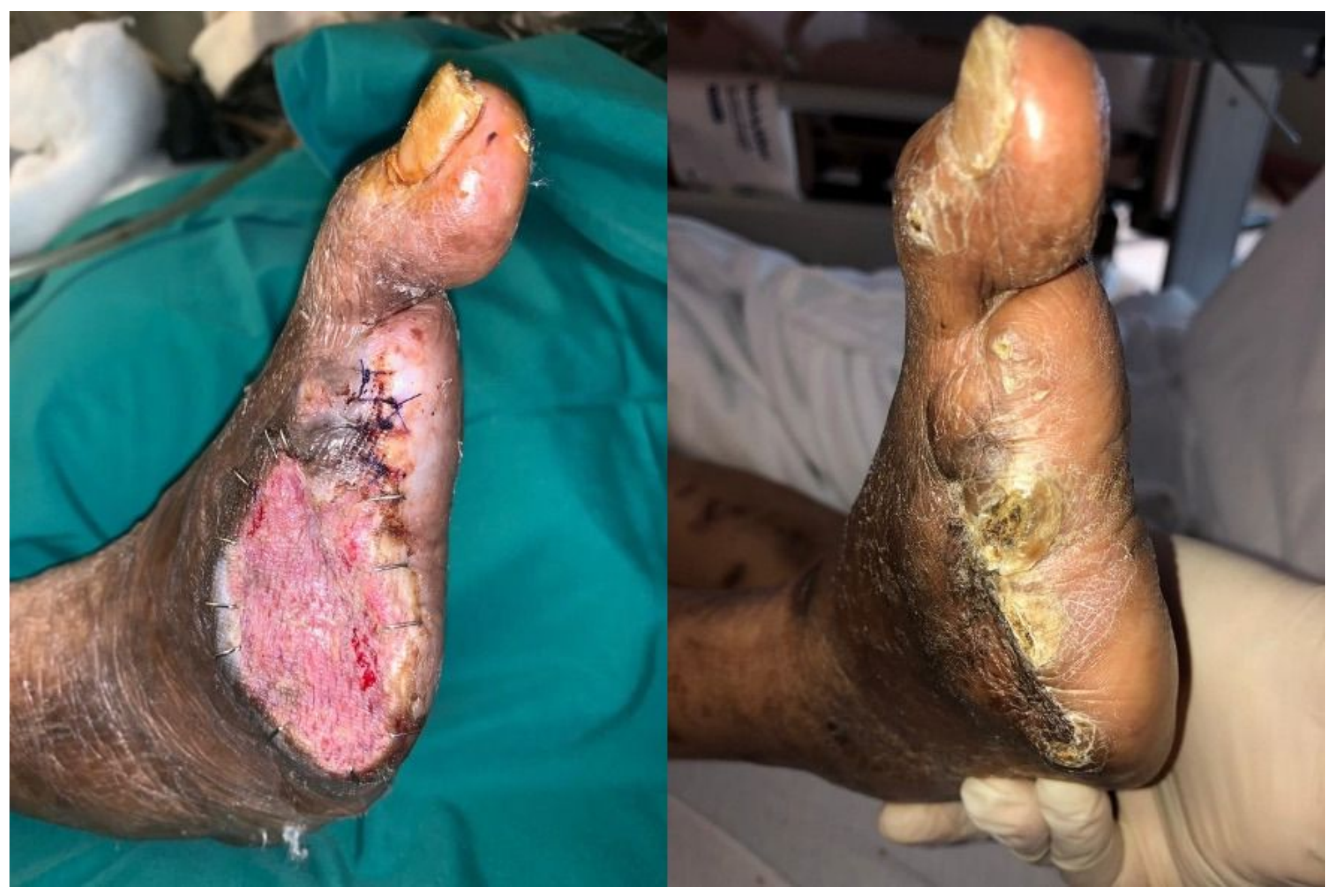

Figure 5

(Left) A Appearance of wound with SSG 42 days after the TOPHAT filleted toe flap technique (Right) B Complete epithelialisation achieved 64 days after the TOPHAT filleted toe flap technique

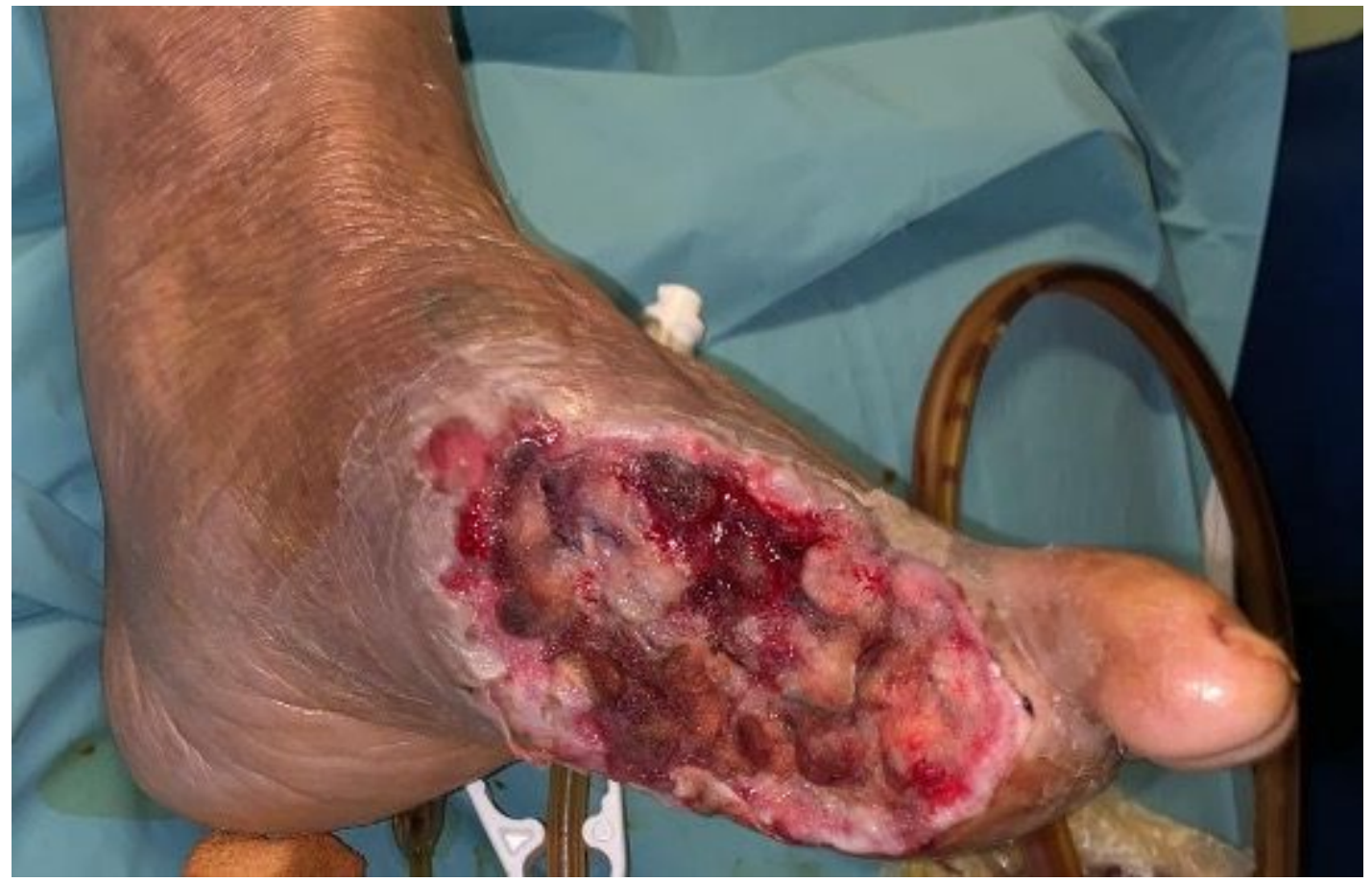

Page 15/16 


\section{Figure 6}

Healthy wound bed 1-week after NPWTi-d therapy but with exposure of the 3rd MTPJ capsule

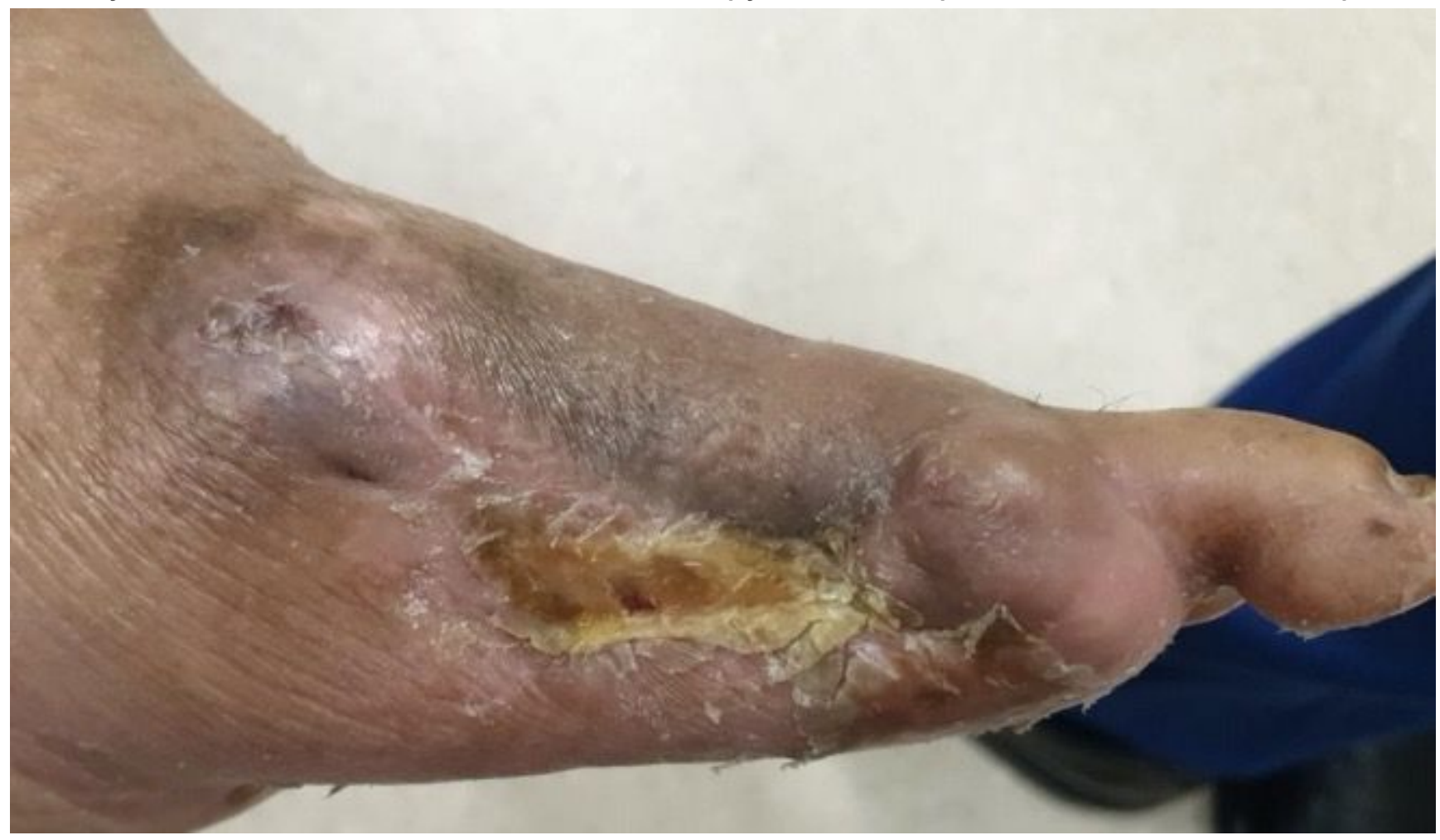

Figure 7

Complete healing by secondary intention 143 days after the TOPHAT filleted toe flap technique 